\title{
Role of Porosity in Dust Cleaning of Silicon Carbide Ceramic Filters
}

\author{
炭化ケイ素フィルターの脱塵性能に及ぼす気孔率の役割 \\ Sang Kuk WOO, Kee Sung LEE, In Sub HAN, Doo Won SEO and Young Ok PARK \\ Korea Institute of Energy Research, Taejon, 305-343, Korea
}

\begin{abstract}
Silicon carbide ceramic filters consisting of highly porous support and filtration layer were fabricated by cold isostatic pressing. The porosities of the supports were varied near the percolation threshold, 28.7, 33.7 and $35.8 \%$. The silicon carbide layer with a finer pore size was coated on the supports to collect dust particles. The pressure drop $(\triangle P)$ was measured at various face velocities, dust loadings, and operation times. The separation efficiency was calculated by measuring the dust concentrations at the inlet and outlet of the filter vessel, and the cleaning efficiency was calculated by comparing the pressure drops before and after back-pulse cleaning. The results indicate that higher porosity of the filter support is favorable for preventing an increase of pressure drop and for improving cleaning efficiency. As the porosity in the silicon carbide filter support increased from $28.7 \%$ to $35.8 \%$, the pressure drop decreased by as much as $30 \%$. Most of dust particles were collected by the finer pores in the coating layer with efficiencies $>99.9 \%$. Additionally, better cleaning efficiency was obtained at higher porosity. The values of flexural strengths of the filter supports were over $20 \mathrm{MPa}$ even though a lower value was found at high porosity.
\end{abstract}

[Received February 19, 2001; Accepted June 21, 2001]

Key-words : Silicon carbide ceramic filter, Porosity, Pressure drop, Separation efficiency, Cleaning efficiency

\section{Introduction}

As harmful particles are usually included in combustion gases, we need to remove the dust particles because high energy-efficiency as well as a cleaner environment is obtained from particle removal. ${ }^{1)}$ More recently, advanced power systems such as integrated gasification combined cycle (IGCC) and pressurized fluidized-bed combustion (PFBC) technologies have been studied for future power generation. ${ }^{2)-4)}$ In these systems, dust particles such as $\mathrm{Na}$, $\mathrm{K}, \mathrm{V}, \mathrm{Ca}$, and $\mathrm{Pb}$ that can be included in the combustion gases act as an origin of erosion of the gas turbine. Therefore the development of a filter is required to remove the dust particles from the combustion gas.

Ceramic filters have one of the greatest potentials for combustion gas cleaning in many kinds of dust removal systems. ${ }^{5)}$ Porous ceramics are appropriate for a filter at high temperature because of superior characteristics such as thermal and chemical resistance. Various types of ceramic filters have been developed for several decades such as candle type, tube type, parallel flow filter, and cross-flow filters. Usually ceramic candle filters are used for hot gas cleaning in the IGCC or PFBC systems. 2),6),7) Recently, attention has been paid to silicon carbide ceramic filters because they have high pressure resistance in comparison to other materials. ${ }^{8)}$ Thus, porous silicon carbide is one of the most favorable materials for combustion gas cleaning, especially in the coal gasification process.

In ceramic filters, control of pore size, porosity, and pore size distribution is indispensable for collecting dust particles. Although it is a critical technology, the effect of porosity on combustion gas cleaning has not been studied much. According to the Percolation theory, the ideal percolation threshold in order to connect the pores to each other is known to $30-40$ volume percent. ${ }^{9)-11)}$ In this study we fabricated silicon carbide candle filter support having porosities around the percolation threshold, $28.7 \%, 33.7 \%, 35.8 \%$. After that, silicone carbide layer with a finer pore size was coated on the filter supports. Then we performed the basic operating test of the filter by feeding dusts at room temperature and atmospheric pressure, and investigated the role of porosity of the filter support in dust cleaning.

\section{Experimental procedure}

\subsection{Fabrication}

Silicon carbide $(\mathrm{SiC})$ powder of mean particle size $\sim 180$ $\mu \mathrm{m}$ was mixed with 3 mass\% clay (Gairome clay, Japan) and 2 mass\% carboxymethyl cellulose (Na-CMC \#6800, Korea Jinseng Products). The mixed powder was kneaded for $1 \mathrm{~h}$ in a sigma-blade mixer with additions of 1 mass $\%$ calcium carbonate $\left(\mathrm{CaCO}_{3}\right.$, Junsei, Japan) and 10 mass $\%$ water. After the mixed batch was dried at room temperature enough to remove the water, we made candle-type green bodies with dimensions of outer diameter $60 \mathrm{~mm}$, inner diameter $40 \mathrm{~mm}$, and length $500 \mathrm{~mm}$ from the kneaded powder by cold isostatic pressing (CIP). The green bodies for the silicon carbide supports were fabricated by control of the forming pressures, $20 \mathrm{MPa}, 30 \mathrm{MPa}$, and $40 \mathrm{MPa}$ to control the porosity (pore total volume).

The coating powder was the same as the powder used to make the filter support, but the particle size was finer. Silicon carbide slurry for coating on the support was prepared from a mix of silicon carbide powder of mean particle size, $14 \mu \mathrm{m}, 0.5$ mass $\%$ clay binder, 0.5 mass $\%$ calcium carbonate, 1 mass \% CMC, 2 mass \% dispersant (7347-C, Sannopco Korea Limited), and defoaming agent (SM-485, Sannopco Korea Limited), using 250 mass\% water as a solvent. The slurry was mixed for $24 \mathrm{~h}$.

The coating slurry was spray coated onto the green body of the silicon carbide support. Spray coating was performed uniformly while maintaining a constant rotation speed of the support. The coated green body was sintered at $1400^{\circ} \mathrm{C}$ for $3 \mathrm{~h}$ in air after removal of water in an oven.

\subsection{Characterization}

The center part of the filter was cut to characterize physical and mechanical properties. Porosities of the supports were calculated using the Archimedes method, and the porosities of the coating layers were checked using an image analyzer after polishing. We used a porosimeter to check the size and size distribution of pores in the support layer. Microstructural characterization was also carried out by SEM (Scanning Electron Microscope) examination. Strength tests were conducted on bar specimens in 3-point flexure. A minimum of 5 specimens $10 \mathrm{~mm} \times 5 \mathrm{~mm} \times 40 \mathrm{~mm}$ 
back-pulse cleaning system

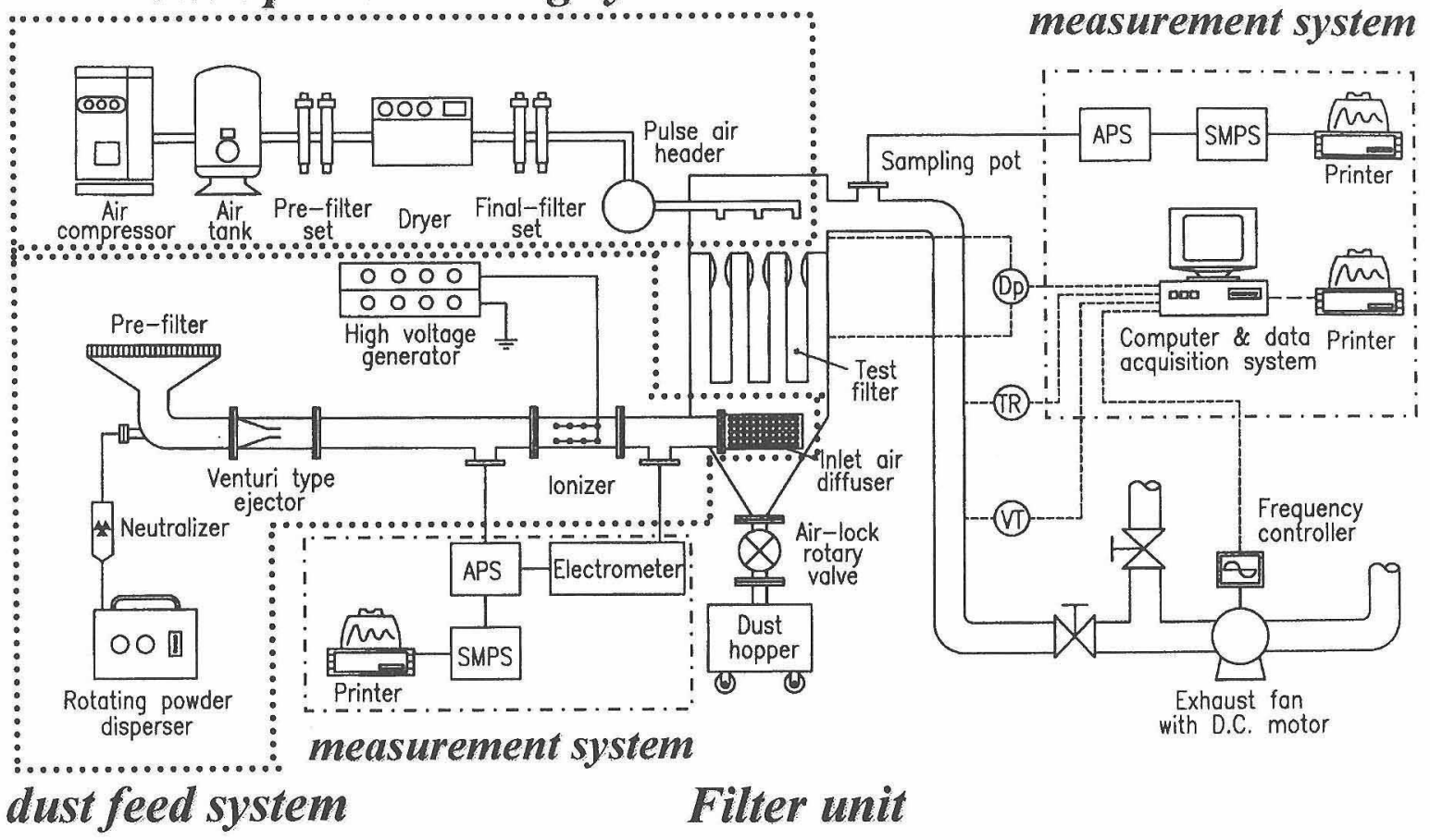

Fig. 1. Schematic diagram of operational test unit.

were cut from the filter supports, edge chamfered, and then fractured at a constant cross-head speed of $30 \mathrm{~mm} / \mathrm{min}$ in the flexure (span length, $1^{\prime \prime}$ ) at room temperature.

We performed an operational test of the filter in the pilotscale filtration unit. Figure 1 shows a schematic diagram of the test unit. The test unit consisted of a dust feed system, filter unit, pulse unit for back-pulse cleaning, and various measurement systems such as pressure loss and dust concentration. All operations were performed at room temperature in air. Quantified dust with an average grain size of 5.2 $\mu \mathrm{m}$, which was previously crushed from fly ash with size $\approx 17.2 \mu \mathrm{m}$, was fed into the filter unit by a screw. The size distribution of the test dusts is shown in Fig. 2. As shown in the figure, the dusts have a uniform Gaussian distribution from 0.9 to $20 \mu \mathrm{m}$ diameter. The dusts were fed from rotating powder disperser and ejected at Venturi type ejector. The dusts were continuously moved by screw revolution and provided to the filter unit through inlet air diffuser. An atmospheric air stream was moved from the bottom to the upper part of the filter unit. The dust loadings were controlled by the revolution speed of the screw feeder. The test time is proportional to the dust loading, dust weight per area of filter, because the feeding rate was linearly proportional to the screw revolution speed. The relationship between 'testing time,' and 'dust loading' in our study is expressed by Eq. (1),

$$
t=\left\{D_{\mathrm{L}} /\left(C_{\mathrm{i}} \times V_{\mathrm{f}}\right)\right\}
$$

where $t$ is testing time $(\mathrm{s}), D_{\mathrm{L}}$ dust loading $\left(\mathrm{g} / \mathrm{m}^{2}\right), C_{\mathrm{i}}$ initial inlet dust concentration $\left(\mathrm{g} / \mathrm{m}^{3}\right), V_{\mathrm{f}}$ face velocity $(\mathrm{m} / \mathrm{s})$. For instance, $200 \mathrm{~g} / \mathrm{m}^{2}$ of dust loadings correspond to $1000 \mathrm{~s}$ of test time at $0.05 \mathrm{~m} / \mathrm{s}$ of face velocity when the inlet dust concentration was fixed at $4 \mathrm{~g} / \mathrm{m}^{3}$. The pressure drop $\left(D_{\mathrm{p}}\right)$ in the filter unit was measured with a pressure transmitter and manometer. The pressure drops without and with dusts were measured. The dust concentration was measured by an APS (aerodynamic particle sizer) at the inlet and outlet and we calculated separation efficiency $(\%)$, defined as,

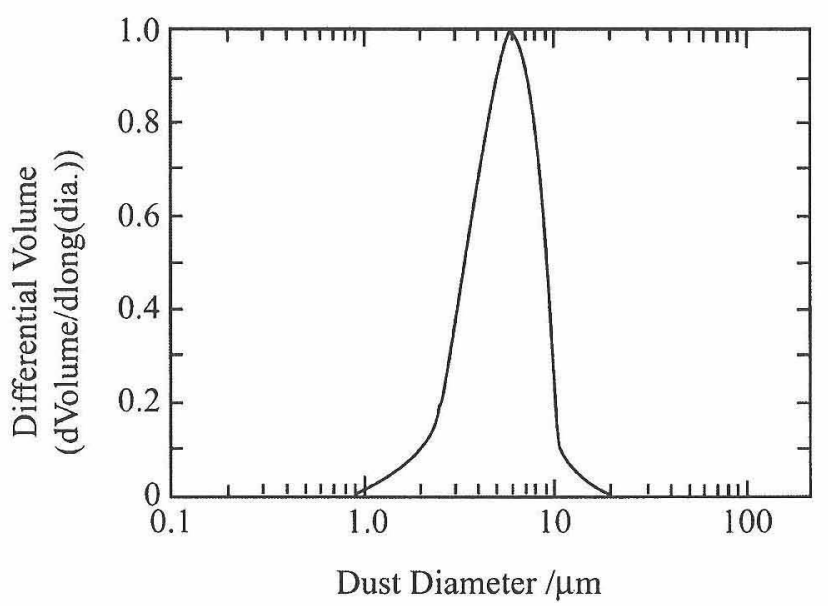

Fig. 2. Size distribution of test dusts.

$$
\eta=\left\{\left(C_{\text {in }}-C_{\text {out }}\right) / C_{\text {in }}\right\} \times 100
$$

where $C_{\text {in }}$ is inlet dust concentration and $C_{\text {out }}$ outlet dust concentration. After the separation, back-pulse cleaning was operated automatically from the inside to the outside of the filter when the pressure drop reached a constant value, 6000 $\mathrm{Pa}$ by injection of compressed air through pulse air header from the top of the filter unit. Here we define the cleaning efficiency $(\%)$ as,

$$
\varepsilon=\left\{\left(P_{\mathrm{f}}-P\right) /\left(P_{\mathrm{f}}-P_{\mathrm{o}}\right)\right\} \times 100 \%
$$

where $P_{\mathrm{f}}$ is $6000 \mathrm{~Pa}, P_{\mathrm{o}}$ is initial pressure drop, and $P$ is a residual pressure drop after a back-pulse cleaning.

\section{Results and discussion}

3.1 Porosity control

In this study, we controlled the porosity of the silicon car- 
bice filter supports by controlling the size of starting powders and the pressure during forming. We used silicon carbide powders, with particle size from $175 \mu \mathrm{m}$ to $250 \mu \mathrm{m}$ to give uniform pore size and distribution. Figure 3 shows the relationship between porosity and forming pressure. The porosity depended on the pressure during forming. It could be controlled from $28.7 \%$ to $35.8 \%$ by varying the forming pressure from $40 \mathrm{MPa}$ to $20 \mathrm{MPa}$. Figure 4 represents the microstructure of filter supports with different porosities, $28.7 \%, 33.7 \%$, and $35.8 \%$. The fractured surfaces of the filters with different porosities are shown in this figure. The micrographs show that the pore volume fraction was controlled well by the pressure during forming.

The strengths of the filter supports were included in Fig. 3. The strength increase with the pressure relates to the improvement of green density by higher pressure. The opposite trend with porosity and strength is in good agreement with prior results. ${ }^{12), 13)}$ Although the strength showed lower values at higher porosity, the strength was estimated at over $20 \mathrm{MPa}$. This high strength is closely related with the inorganic binder. The micrographs in Fig. 4 confirmed that silicon carbide grains are well bonded to each other by the addition of the inorganic binder, 3 mass $\%$ clay and 1 mass $\% \mathrm{CaCO}_{3}$. Most binders helped to bond the $\mathrm{SiC}$ particles to each other because they form a liquid phase during sintering. The binders are believed to exist as a glassy phase after cooling ${ }^{14)}$ which was the main reason for high strength in the filters.

Table 1 shows pore characteristics of silicon carbide filters fabricated at different forming pressures. The

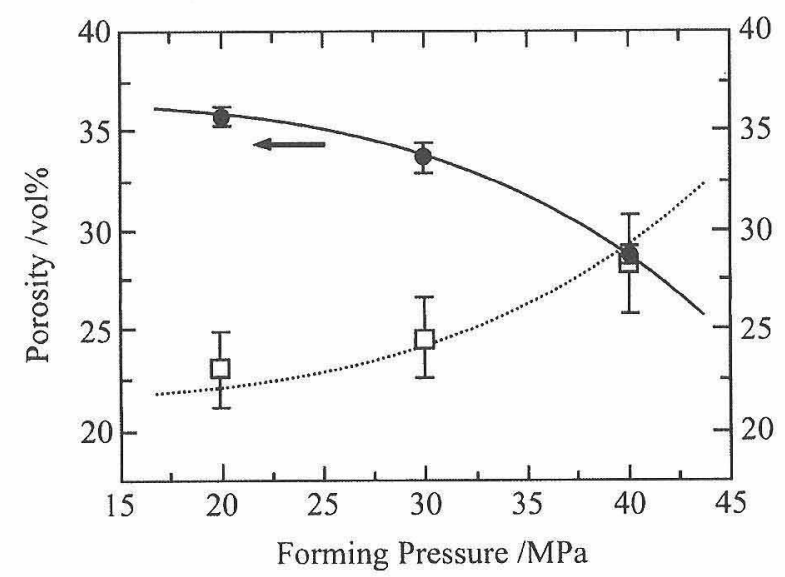

Fig. 3. Porosity and strength as a function of forming pressure; circular data points correspond to porosity and rectangular ones indicate strength data. average pore size of the filter support abruptly decreased as the porosity decreased from $35.8 \%$ to $33.7 \%$, but after that, there was not much change in the pore size. The porosity and pore diameter of the coating layer were also included in the table. All coating thickness was kept constantly, $\sim 200$ $\mu \mathrm{m}$

The pore size distributions of the filter supports showed similar Gaussian distributions to each other as shown in Fig. 5. Note the pore size distribution of the coating layer (Fig. 5(a)) is similar to that of test dusts as shown in the Fig. 2.

\subsection{Pressure drop}

Pressure drop was measured as a function of porosity at various face velocities and dust loadings for silicon carbide filters of different porosities of filter supports, $28.7 \%$, $33.7 \%$, and $35.8 \%$.

Figure 6 shows pressure drop of silicon carbide ceramic filter as a function of porosity of filter supports at various face velocities from $0.03 \mathrm{~m} / \mathrm{s}$ to $0.2 \mathrm{~m} / \mathrm{s}$. The test was operated without feeding dust particles. Note the higher porosity dependence of pressure drop at higher face velocities in Fig. 6, most noticeably at $0.2 \mathrm{~m} / \mathrm{s}$, as commonly encountered with filter resistance during gas permeation.

Figure 7 also represents re-plotted graph from data in Fig. 6. The increase in the pressure drop with increasing face velocity even without dusts indicates that pressure drop is influenced by the filter media itself. The resistance of the filter media increased as the face velocity increased. The linear relationship between pressure drop and face velocity in the Fig. 7 is in good agreement with Darcy's law,

$$
\Delta P=(1 / k) u \cdot \mu \cdot L
$$

where $k$ is specific permeability, $u$ is the face velocity, $\mu$ is fluid viscosity, and $L$ is filter thickness. The permeability $k$ can be calculated from Eq. (4) and the slope in Fig. 7. The higher permeability was found as the porosity in the filter support increased, from $131 \times 10^{-11} \mathrm{~m}^{2}$ (for $28.7 \%$ porosi-

Table 1. Pore Characteristics of Silicon Carbide Ceramic Filter

\begin{tabular}{cccc}
\hline & $\begin{array}{c}\text { Forming } \\
\text { pressure } \\
(\mathrm{MPa})\end{array}$ & $\begin{array}{c}\text { Porosity } \\
(\%)\end{array}$ & $\begin{array}{c}\text { Average } \\
\text { pore } \\
\text { diameter }(\mu \mathrm{m})\end{array}$ \\
\hline Filter support & 20 & 35.8 & 65 \\
& 30 & 33.7 & 45 \\
\hline
\end{tabular}

$\begin{array}{llll}\text { Coating layer } & - & 36.1 & 10\end{array}$

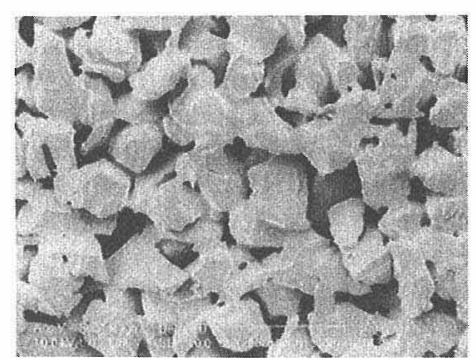

(a)

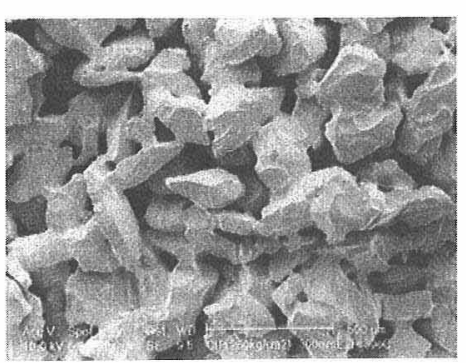

(b)

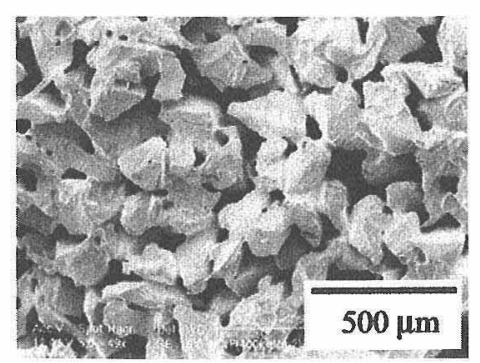

(c)

Fig. 4. SEM micrographs of silicon carbide ceramic filter supports with different porosities, (a) $28.7 \%$, (b) $33.7 \%$ and (c) $35.8 \%$. 


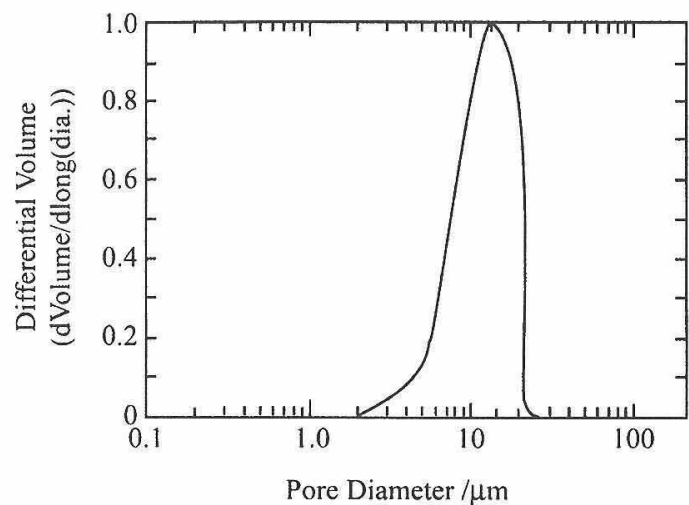

(a)

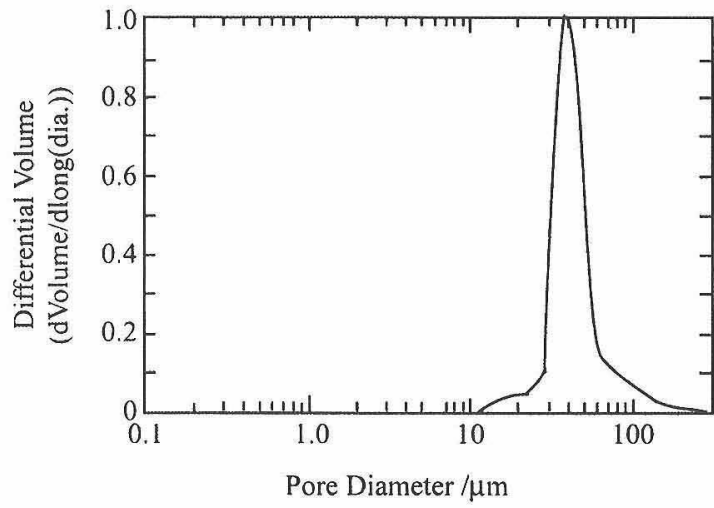

(c)

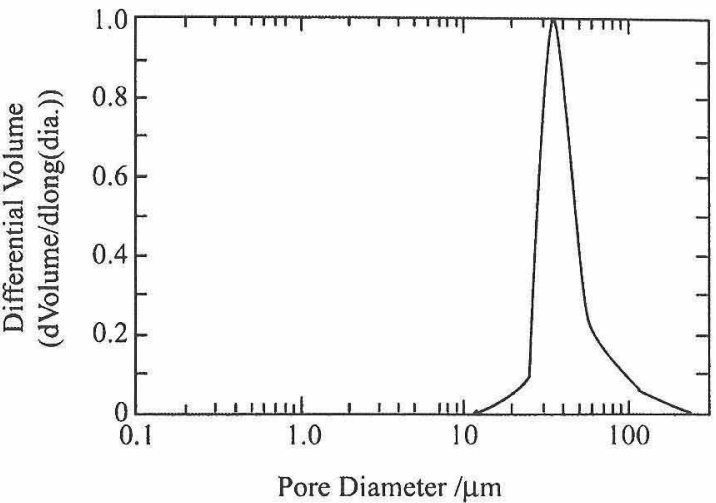

(b)

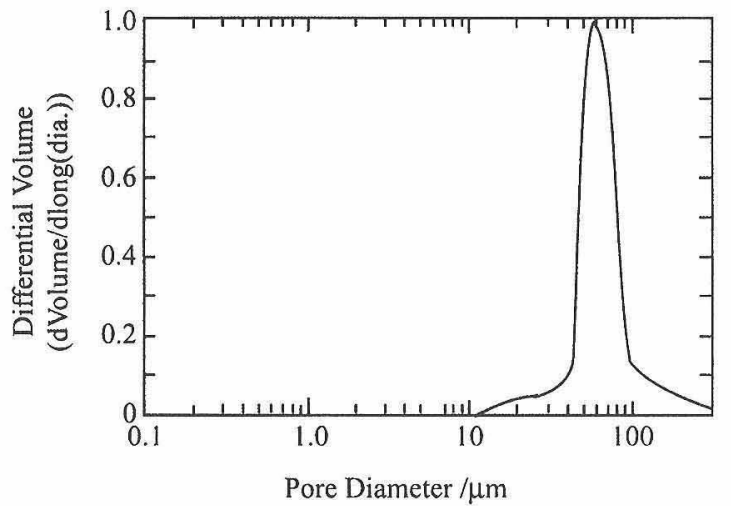

(d)

Fig. 5. Pore size distributions in the silicon carbide ceramic filters, (a) coating layer, substrate layer with different porosities, (b) $28.7 \%$, (c) $33.7 \%$ and (c) $35.8 \%$.

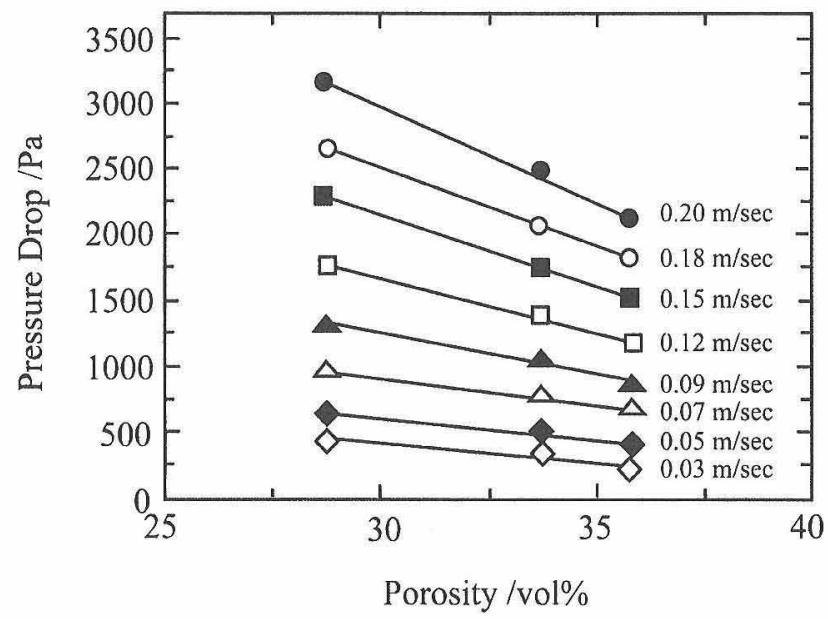

Fig. 6. Pressure drop of silicon carbide ceramic filter as a function of porosity of filter supports at various face velocities.

ty) to $184 \times 10^{-11} \mathrm{~m}^{2}$ (for $35.8 \%$ porosity).

The increase of pressure drop was more pronounced as the dusts were fed into the filter. The pressure drop of silicon carbide ceramic filter as a function of porosity of filter

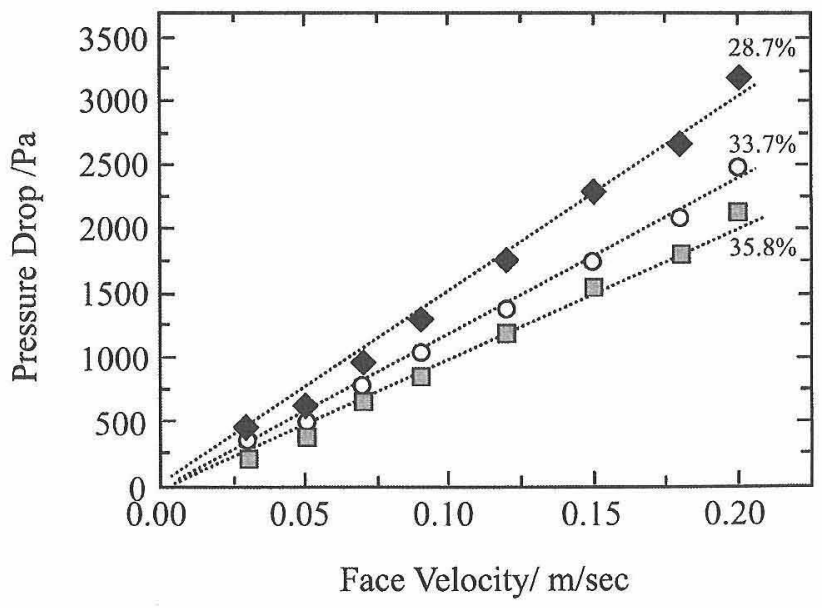

Fig. 7. Pressure drop of silicon carbide ceramic filter as a function of face velocity.

supports at various dust loadings from $0 \mathrm{~g} / \mathrm{m}^{2}$ to $600 \mathrm{~g} / \mathrm{m}^{2}$ was plotted in Fig. 8. The face velocity was fixed at 0.07 $\mathrm{m} / \mathrm{s}$ in all cases. The greater the dust loading, the higher the pressure drop. A comparison of Fig. 8 with Fig. 6 shows that the pressure drop is higher when dusts are fed into the 


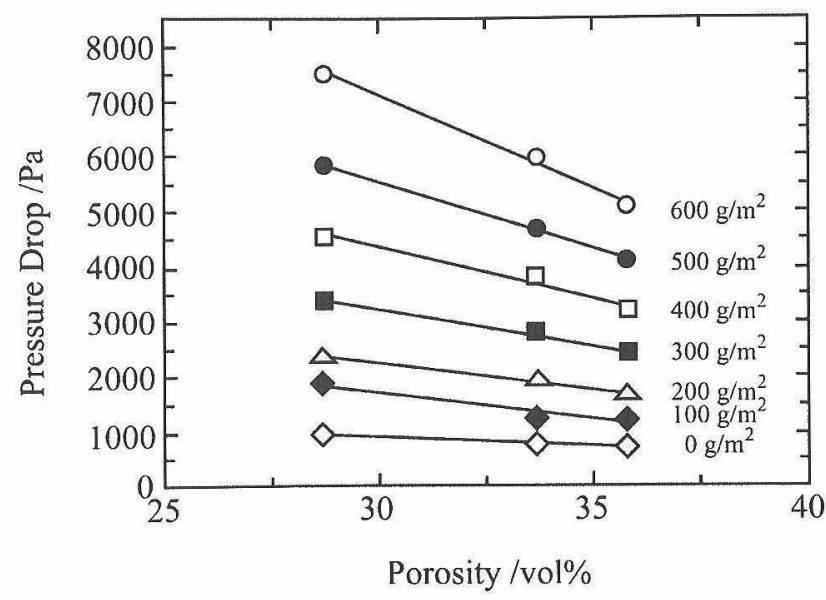

Fig. 8. Pressure drop of silicon carbide ceramic filter as a function of porosity of filter supports at various dust loadings. The face velocity was fixed at $0.07 \mathrm{~m} / \mathrm{s}$.

filter than when no dusts are fed. This result means that the test dusts are being collected and pressed in the test filter. It is expected that dust particles are collected in the fine pore of the coating layer first and form dust layers ${ }^{15}$ ) because the pore size distribution of the coating layer (Fig. 5(a)) is similar to that of test dusts. The packing density and cake thickness of dusts will increase with time, which will cause additional increase of pressure drop.

It is also noteworthy that porosity dependence is more important at higher dust loadings as shown in Fig. 8 (The slope is steepest at dust loading, $600 \mathrm{~g} / \mathrm{m}^{2}$ ). The implication is that resistance of gas flow increases because most of the fine dust penetrates and is captured in fine pores in the coating layer and cannot be removed until back-pulse cleaning is operated. The important issue here is the role of porosity of the filter support in causing pressure drop. Although the particle collection occurrs in the coating layer, the porosity of the filter support greatly affects the pressure drop.

3.3 Separation and cleaning efficiency

Separation efficiency is one of the most important parameters in evaluating characteristics of the filter for combustion gas cleaning. The separation efficiency measured in the filter operation test is shown in Fig. 9. The plotted efficiencies were measured by the Eq. (2) after $1800 \mathrm{~s}$ had passed with a fixed inlet dust concentration of $4 \mathrm{~g} / \mathrm{m}^{3}$. The efficiency was measured at various face velocities for filters with different porosities of the supports. As shown in the Fig. 9, all silicon carbide showed high separation efficiency, $>99.9 \%$, irrespective of filter porosity or face velocity. The result indicates that most of separation successfully occurrs in the fine pores of the coating layer, not in the support layer.

In this study, we only considered fly ashes in atmospheric air as dust particles. However, in a hot combustion environment such as PFBC operation, the dust includes harmful gases $\left(\mathrm{SO}_{2}\right)$, nitrogenous species $\left(\mathrm{NO}_{x}\right)$, and alkali particles. As most of the dusts were collected at room temperature and atmospheric pressure in our study as shown in Fig. 9, it is thought that harmful dusts will be collected even at high temperature. It is expected that the ceramic filter can contribute to the capture of $\mathrm{NO}_{x}$ and $\mathrm{SO}_{x}$ and absorb alkali particles during operation at high temperature by additional chemical reactions as well as by physical entraption. ${ }^{4}$ ) The effect of high temperature and high pressure on the pressure drop and separation efficiency are cur-

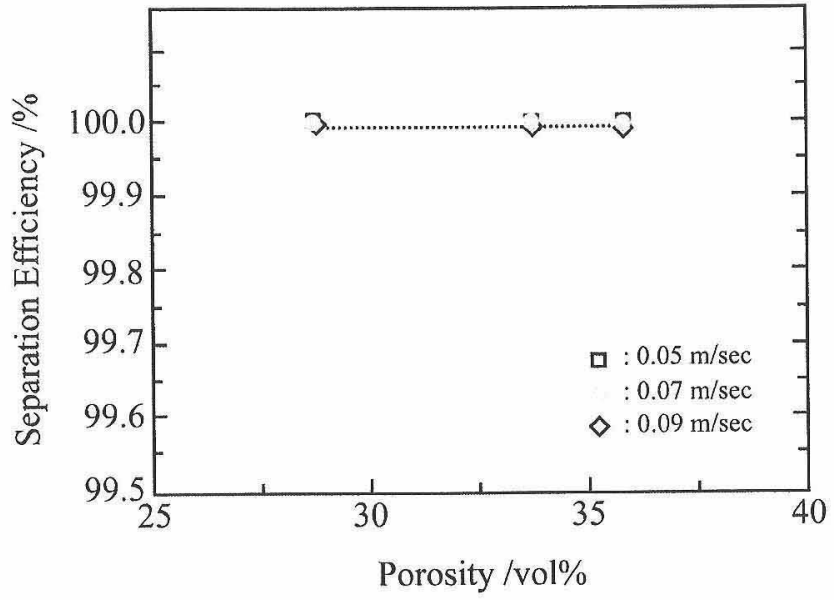

Fig. 9. Separation efficiency of silicon carbide ceramic filter as a function of porosity of filter supports at various face velocities. The inlet dust concentration was fixed at $4 \mathrm{~g} / \mathrm{m}^{3}$.

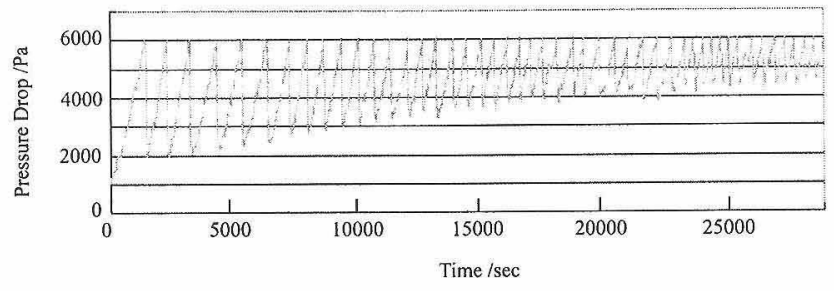

(a)

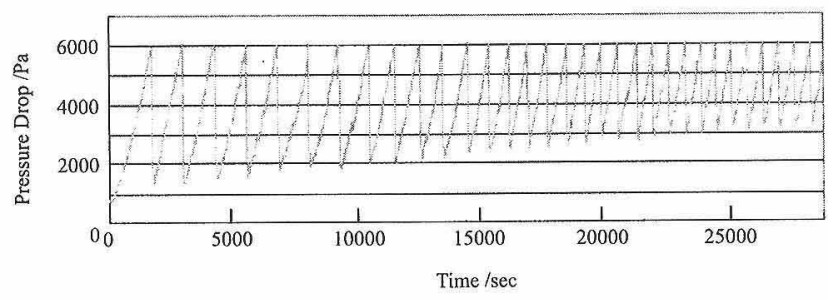

(b)

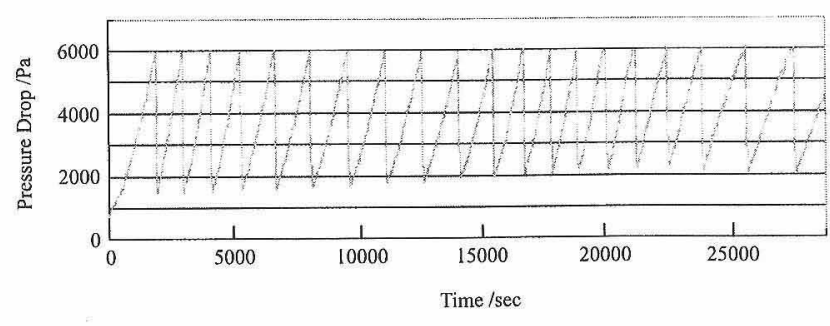

(c)

Fig. 10. Pressure drops of silicon carbide ceramic filters as function of test times. The porosities of filter supports, (a) $28.7 \%$, (b) $33.7 \%$ and (c) $35.8 \%$, respectively.

rently under study.

Figure 10 shows pressure drops of silicon carbide ceramic filters measured during operation time for filters with varying porosity of filter supports. The face velocity and inlet dust concentration was fixed at $0.07 \mathrm{~m} / \mathrm{s}$ and $4 \mathrm{~g} / \mathrm{m}^{3}$, respectively. As the operation time increased, the dust was 


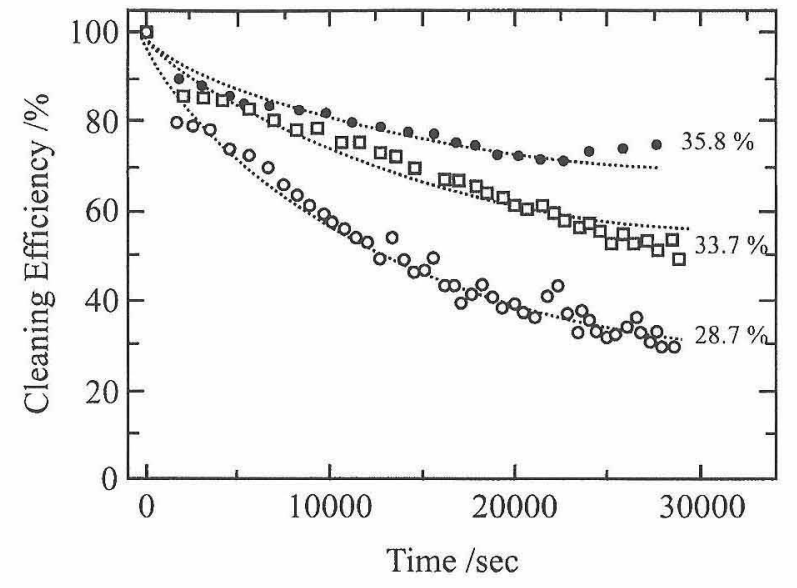

Fig. 11. Cleaning efficiency of silicon carbide ceramic filter as a function of test times. The porosities of filter supports were indicated in the graph.

successfully collected in the finer pores of the coating layer. The pressure drop increased as time passed and the filter surfaces were clogged with dusts at certain stage so backpulse cleaning was required in order to do continuous filtering. In the silicon carbide ceramic filter support with $28.7 \%$ porosity, the time interval required for back-pulse cleaning at $6000 \mathrm{~Pa}$ was the shortest. The complete cleaning was not obtained, so the baseline after back-pulse cleaning was inclined upward. On the other hand, the time interval for back-pulse cleaning was the longest and the baseline after cleaning (residual pressure drop) was almost flat in the silicon carbide ceramic filter support with $35.8 \%$ porosity. The lower the porosity in the filter support, the more frequently the filters need to be blowed back and the greater the operation energy. These results indicate that cleaning of dust deposited on the surface is more favor in the case of a ceramic filter support with higher porosity.

The cleaning efficiencies measured by Eq. (2) were plotted in Fig. 11 for filters with different porosities of the supports. Cleaning efficiency is an important parameter in evaluating filter lifetime because imperfect cleaning ultimately causes clogging of the filter. The packed residual dusts in the coating layer of a filter with a less porous support will prevent continuous separation during the operation test. Therefore it is considerable that the increase of filtering area is not always beneficial because it may cause other problem such as the increase of pressure drop and imperfect cleaning.

\section{Conclusion}

The role of porosity in silicon carbide porous filter sup- ports has been studied. The following results were obtained:

(1) The porosity of ceramic filter supports was controlled by selecting the starting $\mathrm{SiC}$ powder and changing the pressure during forming.

(2) As the porosity increased in the filter support, the strength decreased. However, the strength of all the porous $\mathrm{SiC}$ filter supports was over $20 \mathrm{MPa}$.

(3) The pressure drops were lower at higher porosity values in the filter support. The porosity dependence of the pressure drops increased as the face velocity increased and at the additional dust loadings.

(4) Most of the dust was collected in the silicon carbide coating layer, $>99.9 \%$, at room temperature and atmospheric conditions.

(5) Higher porosity of the support layer was more effective in the back-pulse cleaning. The cleaning efficiency was better for higher porosity. A longer time interval was required for cleaning by back-pulse pressure in the filter support with high porosity.

Acknowledgement The authors would like to express our appreciation to Dr. John Fisher, Dr. Seok Joo Park, and Mr. Jeong Hwan Lim for their helpful discussion and assistance.

\section{References}

1) Ito, S., Tanaka, T. and Kawamura, S., Powder Tech., 100, 32-40 (1998)

2) Stringer, J. and Leitch, A. J., J. Eng. Gas Turb. Power, 114, 371-79 (1992).

3) Choi, J. H., Keum, S. M. and Chung, J. D., Korean. J. Chem. Eng., 16, 823-28 (1999).

4) Duo, W., Grace, J. R., Lim, C. J., Brereton, C. M. H., Watkinson, A. P. and Laursen, K., Ind. Eng. Chem. Res., 38, 260-69 (1999).

5) Ohzawa, Y., Nomura, K. and Sugiyama, K., Mater. Sci. and Eng., A255, 33-38 (1998).

6) Hajek, S. and Peukert, W., Filtration \& Separation, Jan., 29-37 (1996).

7) Chaudhuri, M., Verma, S. R. and Gupta. A., J. Environ. Eng., 120, 1646-51 (1994).

8) Judkins, R. R., Stinton, D. P. and DeVan, J. H., Transactions of the ASME, 118, 500-06 (1996).

9) Davison, A. and Tinkham, M., Phys. Rev., 13, 3261-67 (1976).

10) Kirkpatrick, S., Rev. Mod. Phys., 45, 574-88 (1973).

11) Mclachlan, D. S., Blaszkiewicz, M. and Newnham, R. E., $J$ Am. Ceram. Soc., 73, 2187-203 (1990).

12) Rice, R. W., Mater. Sci. and Eng., A112, 215-24 (1989).

13) Liu, D. M., Ceram. Inter., 23, 135-39 (1997).

14) Westerheide, R., Adler, J., Walch, A., Volker, W., Buhl, H. and Fister, D., "High Temperature Gas Cleaning," Ed. by Dittler, A., Hemmer, G, and Kasper, G., Vol. II, Insitut für Mechanische Verfahrenstechnik und Mechanik der Universität Karlsruhe, Germany (1999) pp. 384-92.

15) Kanaoka, C. and Kishima, T., Proceedings of the 4th Japan-Korea Symposium on Separation Technology, Vol. 2 (1996) pp. 725-28. 